\title{
The innovative medicines initiative (IMI): a shot in the arm for European diabetes research?
}

\author{
P. A. Halban
}

Received: 29 January 2007 / Accepted: 15 May 2007 /Published online: 5 July 2007

(C) Springer-Verlag 2007

Keywords Diabetes research - EURADIA - EFPIA · European Commission $\cdot$ Science policy $\cdot$ Research funding

\begin{tabular}{|c|c|}
\hline \multicolumn{2}{|c|}{ Abbreviations } \\
\hline EASD & European Association for the Study of Diabetes \\
\hline EFPIA & $\begin{array}{l}\text { European Federation of Pharmaceutical } \\
\text { Industries }\end{array}$ \\
\hline EFSD & European Foundation for the Study of Diabetes \\
\hline EURADIA & Alliance for European Diabetes Research \\
\hline FEND & Federation of European Nurses in Diabetes \\
\hline FP & framework programme \\
\hline $\begin{array}{l}\text { IDF- } \\
\text { Europe }\end{array}$ & International Diabetes Federation-Europe \\
\hline IMI & Innovative Medicines Initiative \\
\hline JDRF & $\begin{array}{l}\text { Juvenile Diabetes Research Foundation } \\
\text { International }\end{array}$ \\
\hline$R \& D$ & research and development \\
\hline
\end{tabular}

The academic community has been quite vocal in complaining about inadequate public funding for diabetes research in Europe [1], and rightly so! The intrinsic and relative lack of earmarked research funds (as compared with the USA) for this particular disease area is truly alarming [1], and our public authorities, both national and international, seem unwilling to rise to the challenge. But if we want our strident alarm calls to be seen as constructive criticism rather than complaints, we must be alert to new opportunities and support them if appropriate. While intended to address just a part of a greater problem, and with a relatively modest budget on the grand scale of things, the Innovative

\section{P. A. Halban $(\bowtie)$}

Department of Genetic Medicine and Development,

University Medical Centre,

1 rue Michel-Servet, 1211 Geneva 4, Switzerland

e-mail: philippe.halban@medecine.unige.ch
Medicines Initiative (IMI; for further information see: http://www.imi-europe.org/, last accessed in June 2007) may present us with just such an opportunity.

There is growing concern that Europe is lagging behind its competitors in developing and launching new drugs. This is due in part to considerable under-funding within a fragmented environment characteristic of much European biomedical research [2]. To redress this imbalance, we need closer collaboration between the public (national governments and the European Commission) and private (pharmaceutical companies and small and medium enterprises) sectors, and much more money on the table. Certainly, any collaboration between academic and industry research groups must be part of a package that ensures academic independence and freedom from domination by the evil empire ('Big Pharma' in this particular context). If public funds are involved, as they will be for the IMI, a robust yet transparent competitive review process must be in place, and we should be on our guard to make sure the IMI gets this right. Equally important, any new initiative of this kind must be creative and dynamic in order to capture our imagination and - more important stillimaginative science, and this will involve breaking free from the stranglehold of Brussels and its cumbersome procedures. Let us review the plans in light of these expectations, if not requirements.

To begin with, how did this all come about? The European Commission invited the Research Directors' Group of the European Federation of Pharmaceutical Industries (EFPIA) to develop a European Strategic Research Agenda. Its task was to identify bottlenecks in biomedical research and development (R\&D) [2] and to come up with a plan, the IMI, in order to address them. The goal is to make Europe more competitive, and to benefit patients. The IMI has four major 'pillars':

- Pillar I: improved predictivity of safety evaluation

- Pillar II: improved predictivity of efficacy evaluation 
- Pillar III: knowledge management

- Pillar IV: education and training

Setting aside the appalling bureaucratic language (don't shoot the messenger!), Pillar II is broken down into five disease tracks. Diabetes (the single focus of the 'metabolic diseases' track) is one, alongside cancer, brain disorders, inflammatory diseases and infectious diseases. An IMI diabetes workshop was chaired by V. Koivisto, and leading specialists from all diabetes stakeholders were consulted [2]. The major research focus for the IMI will be precompetitive research, allowing several companies to work together with academic institutions without the usual constraints of the competitive phases of R\&D. Understanding disease mechanisms will be critical, as will the validation of surrogate markers. There will be ample scope for academic groups to get involved. For those of us who have been campaigning for increased awareness of the burden of diabetes and the need for increased research funding in this disease area, it is rewarding to read the preamble to this part of the Strategic Research Agenda (see box) in addition to the major aims [2].

'This disease was chosen from the vast variety of metabolic diseases as diabetes is associated with a number of other metabolic abnormalities, such as obesity, dyslipidaemia and metabolic syndrome. In addition, the prevalence of diabetes is expanding in an exponential manner from the current 150 million to approximately 250 million in the next 15 years. This disease and its complications cause not only human suffering, but it is also a major economic burden for the society. There is a huge unmet medical need for pharmaceutical therapies for the prevention, treatment and cure of diabetes. The group has identified five major research priorities:

- Develop more predictable in vitro, in vivo and in silico pre-clinical models for diabetes and its complications;

- Identify and validate novel targets in diabetes by discovery research in the pathophysiology of the disease and its complications;

- Identify and validate biomarkers for beta-cell function and loss, for treating both insulin resistance and diabetic complications;

- Characterise subpopulations and patient groups using genomics and biomarkers for focused therapeutic and preventive studies;

- Develop quality-of-life and patient-reported outcome metrics to measure the impact of novel treatments on daily activities, and the overall benefits of novel therapy.'
The objective is to involve all key stakeholders (pharmaceutical industry, academic institutions, patients, regulators, major associations and the European Community) in a collaborative fashion. The proposed budget for the IMI as a whole is a substantial $€ 2$ billion for the period 2007-2013, even if only a drop in the ocean in the larger context of the objectives of the Lisbon Summit (which aimed for an R\&D intensity of at least 3\% in Europe). Since this is intended as a generic funding scheme, rising above individual diseases to address the larger problem of competitiveness in Europe, the amount of funding available for any particular disease area, such as diabetes, is small. The budget is to be divided equally between the European Commission (EC) and industry (EFPIA members). Accordingly, if the IMI budget is approved, this will result in a total investment from the EC of $€ 1$ billion. The requested budget for the diabetes track is $€ 37.7$ million annually, for a total of $€ 264$ million for this same 7 year period (again with half of this sum contributed by the EC and half by industry). In reality then, if the IMI budget is approved, the EC will spend just $€ 18.9$ million annually on diabetes research in this peculiar context. This is of the same order of magnitude as funding for diabetes research through existing framework grants (sixth and seventh Framework programmes [FP6 and FP7]). The real value to the community will only become apparent once the infrastructure is in place, as will be discussed below. Will applying for these new funds from the IMI (and spending them) be worth the trouble? Will the anticipated added value for the research community - and ultimately the patient - enable us to make a meal from the snack (let's be kind and not mention crumbs) on the table?

The proposed structure indicates that pharmaceutical companies will match EC funds 'in kind', by providing R\&D resources such as staff, laboratory facilities, materials and clinical research, but no cash on the table. EC funding will come from the FP7 budget, and these public funds will be used exclusively to fund academic IMI research or to support small and medium enterprises. So far, so good. Our enthusiasm is tempered by the small print. It is not yet clear to me from which particular pocket this money will come. Without a significant and compensatory increase in the FP7 life sciences budget, as requested by the Research Directorate General, we shall be no better off than before if money intended for diabetes research in existing, conventional FP7 funding instruments is directed towards the IMI. Furthermore, it is difficult to understand why the requested $€ 37.7$ million annually for metabolic diseases (diabetes), although more than three times that for 'infectious diseases', is much less than that for each of the three other disease tracks. This leopard has not changed its spots.

And so it is that I will admit to complaining once again, even if, as should be apparent if you care to read on, I really do admire the concept and goals of the IMI. Is diabetes 
research cheaper than brain research (requested budget $€ 62.3$ million annually)? Is there a less urgent need for new medicines to treat and cure diabetes than inflammatory diseases (requested budget $€ 60$ million annually)? Are the bottlenecks so much more evident for cancer ( $€ 66.7$ million)? Facetious as these questions may be, I need an answer!

Notwithstanding these grumbles, I believe that the IMI is a bold new initiative that offers exciting opportunities to the diabetes research community, and is for the possible benefit of the person with diabetes. Aside from the obvious interest in seeing increased funding for research in Europe, and diabetes research in particular (even if on a far smaller scale than one might have wished), there are other less evident but very positive aspects to the IMI that are in keeping with the aspirations of the European Association for the Study of Diabetes (EASD) and its partner non-profit organisations. The initiative thus proposes an innovative infrastructure for public-private collaboration that should foster much closer ties between academic and industry-based research groups. Funding of academic research will be competitive and subject to peer review even if, as mentioned earlier, we must pay attention to the small print. By EC standards, the IMI is intended to have an unusual degree of autonomy, with its own executive office, scientific committee and board (albeit with equal representation in the first instance from the EC and EFPIA). My natural fear is that we shall still be forced to master 'Brusselspeak' if we are to understand anything about the IMI and to participate in its actions. Will the IMI's independence allow it to function in a scientist-friendly fashion, favouring a less bureaucratic approach than that lamentably familiar to anyone involved with current FP grants? Ideally, the structure would be similar to one proposed at the meeting that the EC Directorate General for Research and EASD organised together in Brussels in November 2004 (Diabetes: Europe rising to the research challenge) and designed to support public-private joint projects through an independent entity. Success will depend upon close co-operation between the interested parties: academic researchers and their representative organisations/associations and industry.

The European Foundation for the Study of Diabetes (EFSD), the EASD's Research Foundation, has positioned itself as one of the leading supporters of European diabetes research. The EFSD has already committed over $€ 40$ million to diabetes research in Europe and its associated states in the form of innovative partnerships, largely with industry. This model works and has already fostered closer co-operation and understanding between our two research communities. The EASD has also been successful over these past years in lobbying for increased public funding for diabetes research, and more specifically from the EC Framework Programmes. This new activity led to the creation of EURADIA (Alliance for European Diabetes Research; http://www.euradia.org/, last accessed in June 2007), a collaboration between non-governmental organisations (EASD, Federation of European Nurses in Diabetes [FEND] International Diabetes Federation Europe [IDF-Europe], Juvenile Diabetes Research Foundation International [JDRF] and Primary Care Diabetes Europe [PCD Europe]) and the pharmaceutical industry (AstraZeneca, Eli Lilly, GlaxoSmithKline, Merck Sharp and Dohme, Novo Nordisk, Sanofi Aventis, Servier). I believe this alliance to be ideally placed to play an important role in the IMI metabolic diseases track, perhaps providing specific help and expertise (notably from the EASD/EFSD) with calls for applications and peer review, a view shared by some members of the EFPIA Research Directors' group. The IMI also aims to include patient groups in its infrastructure and process. Nongovernmental organisations with direct links to individuals with diabetes are members of EURADIA (see above), with a representative of European diabetes patient associations (IDFEurope), a major research foundation largely run and supported by individuals with type 1 diabetes or parents of children with this disease (JDRF), and organisations representing health professionals playing a critical role in the translation of research output to the front line of diabetes care (FEND and Primary Care Diabetes Europe [PCDE]).

Enough dreaming, let's get back to European reality. We may complain that the IMI budget is woefully inadequate from all points of view, but we must put it into context. The IMI is an experiment; it is a radical new departure for the EC. Given the extraordinary political restraints that govern $\mathrm{EC}$ actions, it is not surprising that the requested budget is small. Indeed, even this modest budget has raised eyebrows. Although conceived a few years ago at the request of the EC, the IMI budget has only just been approved by the European Competitiveness Council, in other words, by ministers of the member states. It is already evident that the roll-out of the programme, once fully approved, will be progressive, with substantially reduced funding during the first couple of years. What can members of the EASD and indeed all European diabetes research stakeholders do to help? I believe that the IMI deserves their careful consideration and support. Potentially, there is something (although admittedly rather little in monetary terms) for everyone in this initiative, ideally even for individuals with diabetes. It will be really important to show the EC and the IMI leadership that the European diabetes research community is ready for this new challenge. There may be tough choices to be made regarding how to spend the limited resources made available initially. Not all disease areas may be funded right away; as activists, not complainers, we must see to it that diabetes features among the first.

Is IMI truly a shot in the arm for European diabetes research? No. But if the experiment results in a focused, 
cost-effective, rational, independent and scientist-friendly entity, fostering vital links between research communities and promoting a more competitive Europe, I believe it is well worth pursuing.

Acknowledgements I thank K. Boubekeur (F. Hoffmann-La Roche), V. Koivisto (Eli Lilly and Chair of the IMI diabetes workshop) and S. Hills (Executive Director of EURADIA), for their help in writing this Commentary.

Duality of interest The author is past president of EASD/EFSD and currently serves as Chairman of the EFSD Advisory Board and of
EURADIA. The views expressed in this article are his own and not necessarily those of these organisations.

\section{References}

1. Halban PA, Ferrannini E, Nerup J (2006) Diabetes research investment in the European Union. Nat Med 12:70-72

2. The Innovative Medicines Initiative (2006) The innovative medicines initiative (IMI) strategic research agenda. Available from: http://www.imi-europe.org/DocStorage/PublicSiteAdmin/Publica tions/Innovative $\% 20$ Medicines $\% 20$ Initiative $\% 20$ SRA $\% 20$ Version \%202.0.pdf, last accessed in June 2007 